\title{
Safety and Efficacy of Laparoscopy-Assisted Gastrectomy after Endoscopic Submucosal Dissection for Early Gastric Cancer: A Retrospective Report
}

\author{
Takahisa Suzuki*, Kazuaki Tanabe, Dang Thuc Anh Vu, Toshihiro Misumi, Nobuaki Fujikuni, \\ Noriaki Tokumoto, Hideki Ohdan \\ Department of Gastroenterological and Transplant Surgery, Applied Life Sciences, Institute of Biomedical \& Health Sciences, Hi- \\ roshima University, Hiroshima, Japan. \\ Email: "takahisa-suzuki@hiroshima-u.ac.jp
}

Received October $7^{\text {th }}$, 2012; revised November $10^{\text {th }}$, 2012; accepted November $19^{\text {th }}, 2012$

\begin{abstract}
Background: This study aimed to determine the safety and effectiveness of laparoscopy-assisted distal gastrectomy (LADG) after ESD. Methods: We reviewed patients with gastric cancer who underwent distal gastrectomy after noncurative ESD from May 2000 to July 2010, and classified them into LADG-ESD and open distal gastrectomy (ODG) after non-curative ESD (ODG-ESD). In addition, we analyzed the standard LADG (LADG-standard) during the same period. We retrospectively analyzed surgical outcomes and survival in these 3 groups. Pathological results after gastrectomy were compared between the LADG-ESD and ODG-ESD; Results: Sixty-one patients underwent distal gastrectomy after non-curative ESD. No differences in overall survival were found between the LADG-ESD and ODG-ESD. The average duration to surgery after ESD was 42.4 days. Although the average surgical duration and average length of hospital stay after surgery were longer in the LADG-ESD than in the ODG-ESD, number of LN dissections was statistically identical in these 2 groups. Operative complications in the LADG-ESD (16.0\%) was higher than that in the LADG-standard (3.8\% - 8.2\%) but similar to that in the ODG-ESD (13.9\%). Conclusion: The present study suggests that LADG contributes to the effectiveness of the treatment of choice for non-curative endoscopic resection.
\end{abstract}

Keywords: Early Gastric Cancer; Laparoscopic Gastrectomy; ESD

\section{Introduction}

The most important factor influencing the survival of patients with early gastric cancer (EGC) is the status of lymph node (LN) metastasis. The incidence of LN metastasis is $1 \%-3 \%$ for mucosal cancers and $11 \%-20 \%$ for submucosal cancers [1]. Guidelines for the treatment of gastric cancer proposed by the Japanese Gastric Cancer Association indicate that patients with mucosal cancer can be managed by endoscopic mucosal resection (EMR) orgastrectomy [2,3]. Endoscopic submucosal dissection (ESD), which involves direct dissection along the submucosal layer, is a new development in endoscopic techniques. This allows the en-bloc resection of large lesions, which results in lower local recurrence rates than those observed after the piecemeal resection of EMR [4,5]. ESD is not limited by lesion size, and it is predicted to replace conventional surgery in treating certain stages of EGC. However, ESD still has a higher

${ }^{*}$ Corresponding author. complication rate than does standard EMR, and it requires high levels of endoscopic skill and experience [6]. ESD has been proposed as a potentially curative treatment for intestinal-type EGC without LN metastases [3, 7,8].

Patients with submucosal cancer are candidates for gastrectomy with LN dissection [9]. Laparoscopic gastrictomy, which has become a promising method of surgical treatment for patients who are diagnosed with EGC, has many advantages over open gastrectomy including cosmetic benefits, less pain, earlier recovery of gastro-intestinal movement, shorter hospital stay, equality of survival, and better quality of life [10-18].

Endoscopic resection allows complete pathological staging of the cancer, which is critical because this allows stratification and refinement of further treatment.

As the number of ESDs for EGC increases, the number of patients who require additional gastrectomy with LN dissection after non-curative ESD is increasing. ESD may cause intra-abdominal adhesions, making additional 
laparoscopic gastrectomy technically difficult $[19,20]$. We retrospectively evaluated the safety and efficacy of laparoscopy-assisted distal gastrectomy (LADG) after noncurative ESD.

\section{Patients and Methods}

We retrospectively analyzed surgical outcomes and survival in patients who underwent distal gastrectomy after non-curative ESD for EGC from May 2000 to July 2010. Clinico pathological characteristics were reviewed retrospectively from prospectively collected medical records. EGC was defined as a lesion confined to the mucosa or submucosa, regardless of the presence or absence of $\mathrm{LN}$ metastases, according to the Japanese Classification of Gastric Carcinoma, $2^{\text {nd }}$ English edition [2,21,22]. noncurative ESD was defined as the presence of cancer cells in the lateral (anterior, posterior, proximal, or distal) margins, presence of cancer cells at the deepest margin, invasion of the submucosa or muscularis propria, presence of lymphatic vessel invasion, or undifferentiated cell type. Patients with any of these criteria required gastric resection and D2 or D1 + LN dissection. Patients who had undergone surgery for specific conditions such as gastric perforation or uncontrolled bleeding during ESD and those subjected to piecemeal resection were excluded from this study. Pathology results obtained after gastrectomy were compared with those obtained after non-curative ESD.

Statistical analyses were carried out for overall survival, duration of surgery, blood loss, postoperative complications, and the length of the postoperative hospital stay. We referred to a large series reported from the Japan Society for Endoscopic Surgery, the standard results in Japan.

\section{Statistical Methods}

Continuous values are expressed as mean (standard deviation [s.d.]). Unavailable analysis was performed using the chi-squared method or Fisher's exact test forcategorical data. A binary logistic regression model was used for multivariable statistical comparisons. P values $<0.05$ were considered statistically significant. Statistical analyses were carried out using SPSS software version 18.0 (SPSS, Chicago, Illinois, USA).

\section{Results}

\subsection{Patient Characteristics}

A total of 1567 patients underwent ESD or EMR during the study period in our hospital from May 2000 to July 2010. Since 2000, Laparoscopic gastrectomy has been performed to patient who was diagnosed early gastric cancer in our hospital. Since 2007, Laparoscopic gastric- tomy after ESD has been performed as standard additional treatment after ESD. So, from 2000 to 2006, gastrectomy after ESD was mainly performed by open surgery, and after 2007 it was performed by laparoscopic surgery. Reconstruction method was changed from B-I to RY around 2007. A total of 100 patients (6.4\%) required additional surgical resection, and 10 patients were excluded from this study because of emergent surgery. The reason of emergent surgery was uncontrolled bleeding, perforation and pan peritonitis, occurred by ESD accidentally. A total of 90 patients (median age, 66 years; range, 21 - 86 years) underwent surgical resection from May 2000 to July 2010. Distal gastrectomy after ESD was performed in 61 patients (median age, 68.8 years; range, 50 - 86 years) (Figure 1). LADG-standard group was diagnosed early gastric cancer, and performed laparoscopic assisted distal gastrectomy since 2000.

Overall survival was not different between LADGESD and O-DG groups ( $\mathrm{P}=0.245)$ (Figure 2). The final pathological diagnosis after gastrectomy showed that the residual tumor was not found in the resected stomach. LN metastases were found in 7 patients (Table 1). Positive LNs were limited within the perigastric LN station according to the Japanese Classification of Gastric Carcinoma, $2^{\text {nd }}$ English edition [21]. All 7 tumors showed submucosal invasion and intestinal type in Lauren's classification. No differences were found between tumor type and infiltration. Three of these patients had lymphatic invasion (ly1) in the ESD pathology specimen, and all 3 of them had vessel invasion (v1). One patient with LN metastases (\#3, \#7, and \#8a) had a recurrence and died with liver metastasis 489 days after surgery.

\subsection{Surgical Outcomes (Table 2)}

The average length of the interval to operation from ESD

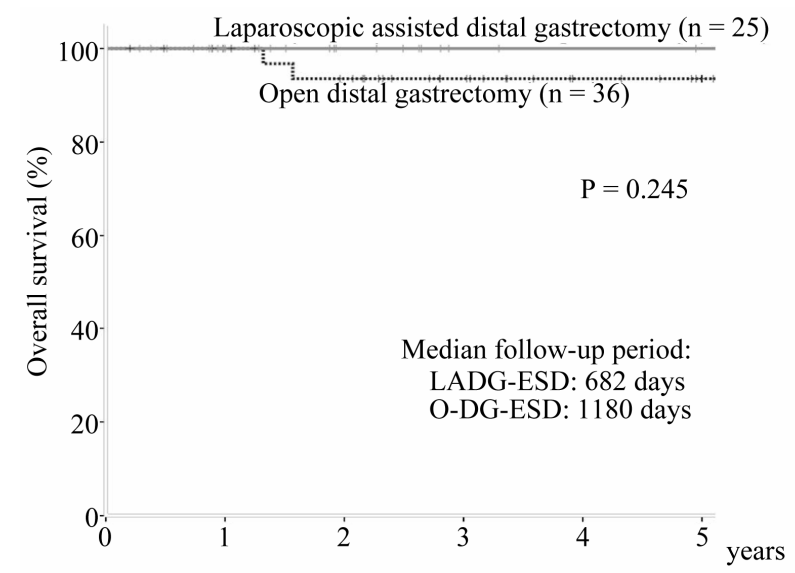

Figure 1. A total of 90 patients were selected among patients that underwent gastrectomy over a period of 10 years, 61 of whom underwent distal gastrectomy. 


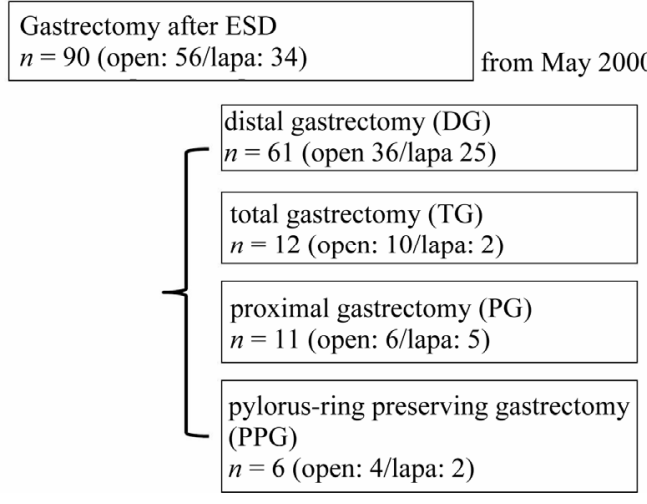

Figure 2. The median follow-up period different among the LADG group (682 days) and the open gastrectomy group (1180 days). The overall survival did not differ between these 2 groups.

was 42.4 days (range, 12 - 111 days). The ODG group after ESD (ODG-ESD) was mainly reconstructed by the Billroth I method, while the LADG group was mainly reconstructed by the Roux en Y method. The number of harvested LNs did not differ in the 3 groups (Figure 3 ). Statistical differences were found in the blood loss and duration of surgery between the ODG-ESD and LADG(ESD/standard) groups $(\mathrm{P}<0.01)$ but not between the LADG-ESD and LADG-standard groups. Surgery-related mortalities did not occur (Figure 4). The portion of the stomach (upper third [U], middle third [M], and lower third [L]), the parts of the gastric circumference (anterior wall [Ant], posterior wall [Post], lesser curvature [Less], or greater curvature [Gre]), and the size of the revealed mucosa were not associated with operation parameters such as duration of surgery, blood loss, and complications.

\subsection{Complications (Table 3)}

Operative complications such as minor an astomotic leakage and pancreatic fistula were observed in $16.0 \%$ of the LADG-ESD group; this incidence was higher than that in the LADG-standard group (3.8\% - 8.2\%) but similar to that in the ODG-ESD group (13.9\%). Journal of Japan Society for Endoscopic Surgery (JSES) was reported 10355 operation (LADG) data in 2008-2009 in major Hospital in Japan. In our hospital, complication after surgery occurred in 9 patients. The mean time from ESD to gastrectomy in these patients was 39.6 days, which was not statistically different from the average. Furthermore, 4 of these 9 patients had preoperative complications such as diabetes, anemia, loss of oral intake, and stroke. The American Society of Anesthesiologists Performance Status (ASA-PS) of these patients was grade 2 or 3 .

\section{Discussion}

ESD is a novel endoscopic procedure that can facilitate

Table 1. Baseline characteristics. No residual cancer after gastrectomy: lymph node (LN) metastasis cases (n $=7)$; $L N$ metastasis was found in 7 patients; the depths of invasion were all sub mucosal with intestinal type histology. No differences were found between tumor type and infiltration.

\begin{tabular}{|c|c|c|c|c|c|c|c|c|c|c|}
\hline & Type & Histological type & Depth of invasion & Interstitial infiltration & INF & ly & $\mathrm{v}$ & LM & VM & $\mathrm{N}$ \\
\hline 1 & 0-Iia & intestinal & $\operatorname{sm} 2$ & Intermediate & $\beta$ & ly2 & v2 & - & + & 1/61 \#4d \\
\hline 2 & 0-Iic & intestinal & $\operatorname{sm} 2$ & Intermediate & $\beta$ & ly1 & v1 & - & - & 1/38\#4d \\
\hline 3 & 0-Iic & intestinal & $\operatorname{sm} 2$ & Medullary & $\beta$ & ly0 & v0 & - & - & 1/39\#5 \\
\hline 4 & 0-Iia & intestinal & sm2 & Intermediate & $\beta$ & ly0 & v0 & - & + & 1/51\#1 \\
\hline 5 & 0-Iic & intestinal & $\operatorname{sm} 2$ & Medullary & $\alpha$ & ly1 & v0 & - & - & $1 / 84 \# 6$ \\
\hline 6 & 0-Iic & intestinal & $\operatorname{sm} 2$ & Intermediate & $\beta$ & ly1 & v0 & - & - & $1 / 34 \# 5$ \\
\hline 7 & 0 -I & intestinal & $\operatorname{sm} 1$ & Intermediate & $\beta$ & ly0 & $\mathrm{v} 1$ & - & + & $\begin{array}{c}\text { 3/45\#3\#7\#8a } \\
\text { death with liver metastasis }\end{array}$ \\
\hline
\end{tabular}

Table 2. Surgical outcome. The open DG after ESD group was mainly reconstructed by the Billroth I method (B-I) and the LADG group was mainly reconstructed by the Roux en Y method (RY).

\begin{tabular}{cccc}
\hline & ODG-ESD (36) & LADG-ESD (25) & LADG-standard (78) \\
\hline Sex (M/F) & $24 / 12$ & $19 / 6$ & $46 / 32$ \\
Age & $68.2(52-86)$ & $69.8(50-85)$ & \\
reconstruction method & & 4 & $21.6(32-82)$ \\
B-I & 27 & 0 & 0 \\
B-II & 2 & 21 & 57 \\
RY & 7 & & 21 \\
\hline
\end{tabular}


Table 3. Complications JSES: Journal of Japan Society for Endoscopic Surgery LADG (JSES 2008-2009).

\begin{tabular}{ccccc}
\hline & ODG-ESD (36) & LADG-ESD (25) & LADG-standard (78) & LADG (JSES 2008-2009) (10355) \\
\hline Complications & $5(13.9 \%)^{*}+$ & $4(16.0 \%)^{*}$ & $3(3.8 \%)^{+}$ & $780(7.5 \%)$ \\
postoperative bleeding & 0 & 0 & 0 & $47(0.4 \%)$ \\
stenosis & $2(5.6 \%)$ & 0 & $1(1.3 \%)$ & $206(2.0 \%)$ \\
failure of the sutures & 0 & $1(4.0 \%)$ & 0 & $113(1.0 \%)$ \\
intra-abdominal abscess & $2(5.6 \%)$ & $2(8.0 \%)$ & $2(2.6 \%)$ & $76(0.7 \%)$ \\
pancreatitis & 0 & $1(4.0 \%)$ & $1(1.3 \%)$ & $130(1.25 \%)$ \\
bowel obstruction & $1(2.8 \%)$ & $1(4.0 \%)$ & 0 & $20(0.2 \%)$ \\
infection & 0 & $1(4.0 \%)$ & 0 & $77(0.7 \%)$ \\
others & 0 & 0 & 0 & $47(0.5 \%)$ \\
\hline
\end{tabular}

${ }^{*} \mathrm{P}<0.01 ;+\mathrm{P}<0.01$

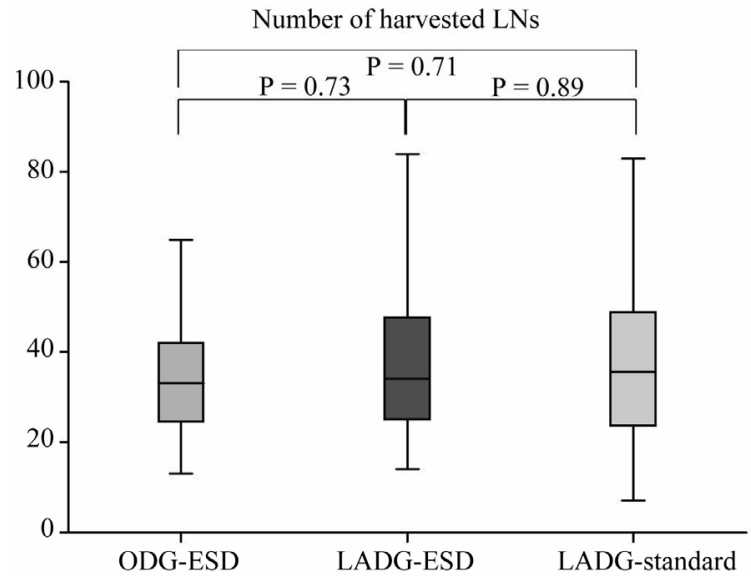

Figure 3. Surgical outcomes in the open-DG group and the LADG group after ESD. The open gastrectomy and LADG groups showed statistical differences in blood loss and duration of surgery but did not show differences in the number of harvested lymph nodes (LNs) or the hospital stay after surgery. This result indicates that the LADG-ESD group was non-inferior to the LADG-standard and ODGESD groups regarding the quality of the operation.

en-bloc resection of EGC. Although this is an elegant technique, non-curative ESD has been associated with local recurrence and regional metastases. As the number of ESD treatments has increased, a gradual increase has been observed in the number of additional gastrectomies required after non-curative ESD. Although various minimally invasive treatments have emerged as the best frontline therapies for EGC, there have been no established indications that these treatments are applicable [23]. An additional gastric resection with LN dissection is inevitable after non-curative ESD because of the histological depth, lymphatic duct invasion, and vessel invasion of EGC. Radical gastrectomy should be performed if pathological examination reveals a positive lateral resection margin after ESD [24]. Although surgical indications after non-curative ESD are the subject of considerable
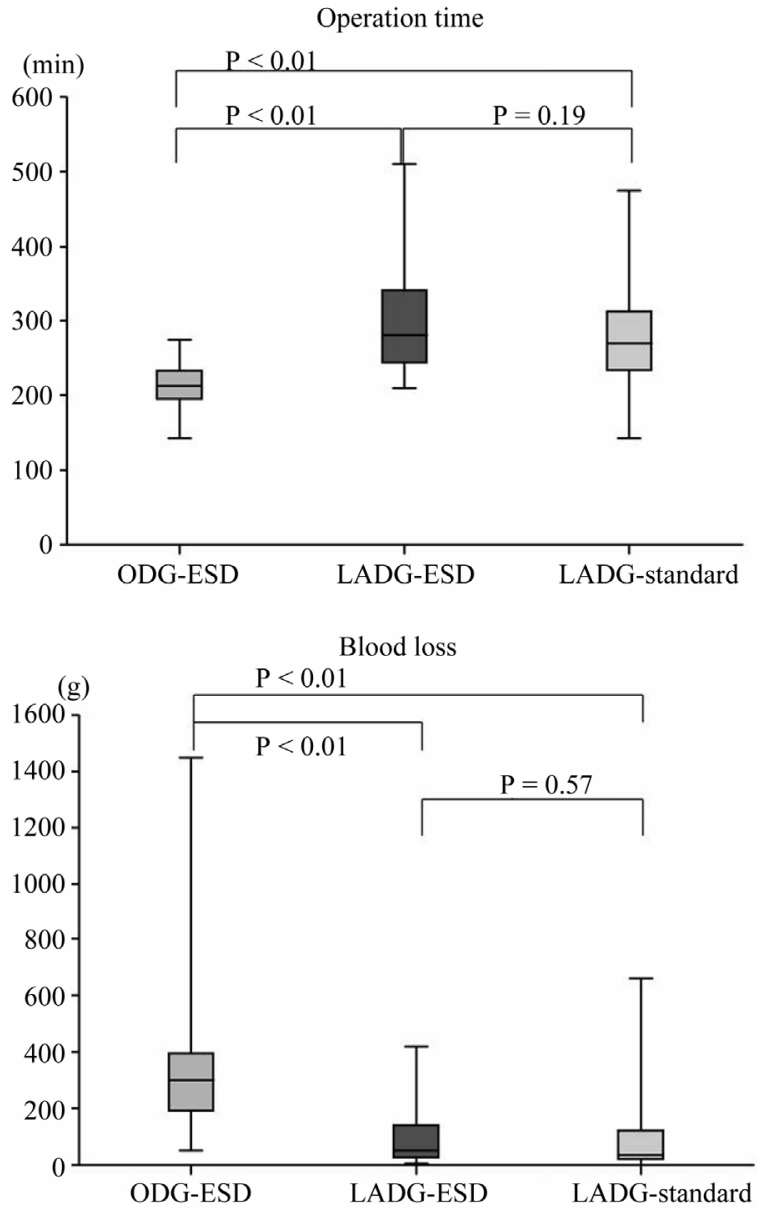

Figure 4. Surgical outcomes in the open-DG groups and LADG groups after ESD. A statistical difference in blood loss and duration of surgery was found between the open gastrectomy and LADG groups.

concern andcontroversy, few reports have been published on this topic. One study suggested that surgery should be performed when pathological examination of the ESD specimen reveals tumor invasion beyond the 
middle third of the submucosa (sm2) or a mucosal cancer larger than $3 \mathrm{~cm}$ [25]. Another study concluded that surgery should be performed if the following independent risk factors [1] for LN metastasis are present: width of submucosal invasion $>6000 \mu \mathrm{m}$, lymphatic involvement, undifferentiated type at the deepest invasive portion, depth of submucosal invasion $>1000 \mu \mathrm{m}$, and tumor diameter $>30 \mathrm{~mm}$. These 5 independent risk factors may allow expansion of the criteria for determining whether endoscopic resection for submucosal invasive gastric cancer has been curative [1].

After ESD, large artificial ulcerations $(>25 \mathrm{~mm})$ and intra-abdominal adhesions are often observed, which makes additional laparoscopic gastrectomy difficult [19].

Since its introduction in 1994, LADG has become an increasingly popular method for the surgical treatment of patients with EGC [15,26]. Recently, many surgeons have stated that this procedure is feasible and safe.Some have suggested that laparoscopic gastrectomy with D1 + $\beta(\mathrm{D} 1+7,8 \mathrm{a}, 9$ nodes dissection) dissection, according to the Japan Gastric Cancer Assosiation classification, $2^{\text {nd }}$ English edition [21], should be the treatment of choice for non-curative endoscopic resection [27].

This study aimed to compare the safety and efficacy of LADG with those of open gastrectomy in the treatment of EGC after ESD. From 2000 to 2006, gastrectomy after non-curative ESD was mainly performed by open surgery, and after 2007 it was performed by laparoscopic surgery. Reconstruction method was changed from B-I to RY around 2007. As a result median follow-up periods between LADG-ESD and ODG-ESD was different, and the median follow-up period in the LADG-ESD group (682 days) may be insufficient to support any long-term outcomes, because this study was retrospective study. No statistical difference was found in the incidence of complications or overall survival between the ODG-ESD and LADG-ESD groups. Furthermore, the LADG-ESD and LADG-standard groups did not show a statistical difference in blood loss or duration of surgery. This result indicates that the LADG-ESD group was non-inferior to the LADG-standard and ODG-ESD groups regarding the quality of the operation. The incidence of complications in cases of gastrectomy after ESD (LADG-ESD and ODG-ESD groups) was higher than that in cases of standard gastrectomy, but the incidence of complications was not different between the LADG-ESD and ODG-ESD groups. The result is there are no statistical differences in surgical results (overall survival, blood loss, number of LN dissections, hospital stay, and complications) between the ODG-ESD and LADG-ESD. LADG has been applied to the treatment of gastric cancer, and there are now several publications regarding its safety and feasibility. An advantage of LADG is minimally invasive surgery. Nine of our patients had complications after surgery. The mean time from ESD to gastrectomy in these 9 patients was 39.6 days, which was not statistically different from the average (42.4 days). Furthermore, 4 out of these 9 patients had preoperative complications such as diabetes, anemia, loss of oral intake, and stroke and the ASA Performance Status was 2 or 3 . This result suggests that it is important to pay attention to and control preoperative complications before LADG for highrisk patients.

The formation of intra-abdominal adhesions results from the healing of the ulceration caused by ESD as well as from the healing of the ulceration and chronic gastritis caused by Helicobacter pylori infection. One study reported that the formation of intra-abdominal adhesions depends on the interval from ESD to gastrectomy [19]. Considerable controversy exists regarding the timing of LADG after non-curative ESD. In the case of acute cholecystitis, a systematic review with meta-analysis of randomized controlled trials reported no significant difference in complications or conversion rates when laparoscopic cholecystectomy was performed at presentation with acute cholecystitis or 6 - 12 weeks after the symptoms had settled $[28,29]$. It is difficult to select the best time for performing additional gastrectomy after ESD for intra-abdominal adhesions. Before undergoing additional laparoscopic gastrectomy, all of our patients were prescribed anti-ulceration drugs, such as proton pump inhibitors and muco protective agents, until the artificial ulceration had reached the healing or scarring stage. The average interval to surgery from ESD was 42.4 days (range, 12 - 111 days) in our study. Further examinations are required to evaluate the role of this interval on formation of intra-abdominal adhesions. In contrast to our expectations, we found that the portion of the stomach $(\mathrm{U}$, $\mathrm{M}$, or $\mathrm{L}$ ), the portion of the gastric circumference (Ant, Post, Less, or Gre), and the size of the revealed mucosa were not associated with surgical parameters such as duration of surgery, blood loss, and complications.

In conclusion, the present study suggests that LADG contributes to the effectiveness of the treatment of choice for non-curative endoscopic resection.

\section{REFERENCES}

[1] Y. Sanomura, S. Oka, S. Tanaka, M. Higashiyama, S. Yoshida and K. Arihiro, "Predicting the Absence of Lymph Node Metastasis of Submucosal Invasive Gastric Cancer: Expansion of the Criteria for Curative Endoscopic Resection," Scandinavian Journal of Gastroenterology, Vol. 45, No. 12, 2010, pp. 1480-1487. doi:10.3109/00365521.2010.505659

[2] T. Sano and Y. Kodera, "Japanese Classification of Gastric Carcinoma: 3rd English Edition,” Gastric Cancer, 
Vol. 14, No. 2, 2011, pp. 101-112. doi:10.1007/s10120-011-0041-5

[3] O. Goto, M. Fujishiro, S. Kodashima, S. Ono and M. Omata, "Outcomes of Endoscopic Submucosal Dissection for Early Gastric Cancer with Special Reference to Validation for Curability Criteria,” Endoscopy, Vol. 41, No. 2, 2009, pp. 118-122. doi:10.1055/s-0028-1119452

[4] J. S. Jang, S. R. Choi, W. Qureshi, M. C. Kim, S. J. Kim and J. S. Jeung, "Long-Term Outcomes of Endoscopic Submucosal Dissection in Gastric Neoplastic Lesions at a Single Institution in South Korea," Scandinavian Journal of Gastroenterology, Vol. 44, No. 11, 2009, pp. 13151322. doi:10.3109/00365520903254304

[5] S. Oka, S. Tanaka, I. Kaneko, R. Mouri, M. Hirata and T. Kawamura, "Advantage of Endoscopic Submucosal Dissection Compared with EMR for Early Gastric Cancer," Gastrointestinal Endoscopy, Vol. 64, No. 6, 2006, pp. 877-883. doi:10.1016/j.gie.2006.03.932

[6] T. Gotoda, "Endoscopic Resection of Early Gastric Cancer,” Gastric Cancer, Vol. 10, No. 1, 2007, pp. 1-11. doi:10.1007/s10120-006-0408-1

[7] M. Tanaka, H. Ono, N. Hasuike and K. Takizawa, "Endoscopic Submucosal Dissection of Early Gastric Cancer,” Digestion, Vol. 77, Suppl. 1, 2008, pp. 23-28. doi:10.1159/000111484

[8] R. Takenaka, Y. Kawahara, H. Okada, T. Tsuzuki, S. Yagi and J. Kato, "Endoscopic Submucosal Dissection for Cancers of the Remnant Stomach after Distal Gastrectomy," Gastrointestinal Endoscopy, Vol. 67, No. 2, 2008, pp. 359-363. doi:10.1016/j.gie.2007.10.021

[9] Y. Adachi, N. Shiraishi and S. Kitano, "Modern Treatment of Early Gastric Cancer: Review of the Japanese Experience,” Digestive Surgery, Vol. 19, No. 5, 2002, pp. 333-339. doi:10.1159/000065829

[10] Y. Adachi, N. Shiraishi, K. Ikebe, M. Aramaki, T. Bandoh and S. Kitano, "Evaluation of the Cost for Laparoscopic-Assisted Billroth I Gastrectomy,” Surgical Endoscopy, Vol. 15, No. 9, 2001, pp. 932-936. doi:10.1007/s004640090089

[11] Y. Adachi, N. Shiraishi, A. Shiromizu, T. Bandoh, M. Aramaki and S. Kitano, "Laparoscopy-Assisted Billroth I Gastrectomy Compared with Conventional Open Gastrectomy," Archives of Surgery, Vol. 135, No. 7, 2000, pp. 806-810. doi:10.1001/archsurg.135.7.806

[12] T. Asao, Y. Hosouchi, T. Nakabayashi, N. Haga, E. Mochiki and H. Kuwano, "Laparoscopically Assisted Total or Distal Gastrectomy with Lymph Node Dissection for Early Gastric Cancer,” British Journal of Surgery, Vol. 88, No. 1, 2001, pp. 128-132. doi:10.1046/j.1365-2168.2001.01618.X

[13] Y. W. Kim, Y. H. Baik, Y. H. Yun, B. H. Nam, D. H. Kim and I. J. Choi, "Improved Quality of Life Outcomes after Laparoscopy-Assisted Distal Gastrectomy for Early Gastric Cancer: Results of a Prospective Randomized Clinical Trial,” Annals of Surgery, Vol. 248, No. 5, 2008, pp. 721-727. doi:10.1097/SLA.0b013e318185e62e

[14] H. Hayashi, T. Ochiai, H. Shimada and Y. Gunji, "Prospective Randomized Study of Open versus Laparo-
scopy-Assisted Distal Gastrectomy with Extraperigastric Lymph Node Dissection for Early Gastric Cancer," Surgical Endoscopy, Vol. 19, No. 9, 2005, pp. 1172-1176. doi:10.1007/s00464-004-8207-4

[15] S. Kitano, N. Shiraishi, K. Kakisako, K. Yasuda, M. Inomata and Y. Adachi, "Laparoscopy-Assisted Billroth-I Gastrectomy (LADG) for Cancer: Our 10 Years' Experience,” Surgical Laparoscopy Endoscopy \& Percutaneous Techniques, Vol. 12, No. 3, 2002, pp. 204-207. doi:10.1097/00129689-200206000-00021

[16] G. A. Jeong, G. S. Cho, H. H. Kim, H. J. Lee, S. W. Ryu and K. Y. Song, "Laparoscopy-Assisted Total Gastrectomy for Gastric Cancer: A Multicenter Retrospective Analysis,” Surgery, Vol. 146, No. 3, 2009, pp. 469-474. doi:10.1016/j.surg.2009.03.023

[17] J. H. Lee and H. S. Han, "A Prospective Randomized Study Comparing Open vs. Laparoscopy-Assisted Distal Gastrectomy in Early Gastric Cancer: Early Results," Surgical Endoscopy, Vol. 19, No. 2, 2005, pp. 168-173. doi:10.1007/s00464-004-8808-y

[18] J. Song, H. J. Lee, G. S. Cho, S. U. Han, M. C. Kim and S. W. Ryu, "Recurrence Following Laparoscopy-Assisted Gastrectomy for Gastric Cancer: A Multicenter Retrospective Analysis of 1417 Patients,” Annals of Surgical Oncology, Vol. 17, No. 7, 2010, pp. 1777-1786. doi:10.1245/s10434-010-0932-4

[19] T. Akagi, N. Shiraishi, K. Hiroishi, T. Etoh, K. Yasuda and S. Kitano, "Case Series of Intra-Abdominal Adhesions Induced by Artificial Ulceration after Endoscopic Submucosal Dissection before Additional Laparoscopic Gastrectomy," Gastrointestinal Endoscopy, Vol. 72, No. 2, 2010, pp. 438-443. doi:10.1016/j.gie.2010.03.1066

[20] B. Walter, A. Probst, B. Markl, T. Wagner, M. Anthuber and H. Messmann, "Fulminant Metastatic Spread in a Patient with an Early Gastric Cancer," Endoscopy, Vol. 41, No. 10, 2009, pp. 907-909. doi:10.1055/s-0029-1215062

[21] Japanese Gastric Cancer A, "Japanese Classification of Gastric Carcinoma-2nd English Edition,” Gastric Cancer, Vol. 1, No. 1, 1998, pp. 10-24.

[22] J. G. C. Association, "Japanese Classification of Gastric Carcinoma. 2nd English Edition,” Gastric Cancer, Vol. 1, No. 1, 1998, pp. 10-24.

[23] W. J. Hyung, J. H. Cheong, J. Kim, J. Chen, S. H. Choi and S. H. Noh, "Application of Minimally Invasive Treatment for Early Gastric Cancer,” Journal of Surgical Oncology, Vol. 85, No. 4, 2004, pp. 181-185. doi:10.1002/jso.20018

[24] H. Jung, J. M. Bae, M. G. Choi, J. H. Noh, T. S. Sohn and S. Kim, "Surgical Outcome after Incomplete Endoscopic Submucosal Dissection of Gastric Cancer," British Journal of Surgery, Vol. 98, No. 1, 2011, pp. 73-78. doi:10.1002/bjs.7274

[25] K. W. Ryu, I. J. Choi, Y. W. Doh, M. C. Kook, C. G. Kim and H. J. Park, "Surgical Indication for Non-Curative Endoscopic Resection in Early Gastric Cancer,” Annals of Surgical Oncology, Vol. 14, No. 12, 2007, pp. 3428-3434. doi:10.1245/s10434-007-9536-Z

[26] S. Kitano, Y. Iso, M. Moriyama and K. Sugimachi, 
“Laparoscopy-Assisted Billroth I Gastrectomy,” Surgical Laparoscopy Endoscopy \& Percutaneous Techniques, Vol. 4, No. 2, 1994, pp. 146-148.

[27] K. Y. Song, W. J. Hyung, H. H. Kim, S. U. Han, G. S. Cho and S. W. Ryu, "Is Gastrectomy Mandatory for All Residual or Recurrent Gastric Cancer Following Endoscopic Resection? A Large-Scale Korean Multi-Center Study," Journal of Surgical Oncology, Vol. 98, No. 1, 2008, pp. 6-10. doi:10.1002/jso.21074

[28] E. Wilson, K. Gurusamy, C. Gluud and B. R. Davidson,
"Cost-Utility and Value-of-Information Analysis of Early versus Delayed Laparoscopic Cholecystectomy for Acute Cholecystitis," British Journal of Surgery, Vol. 97, No. 2, 2010, pp. 210-219. doi:10.1002/bjs.6872

[29] K. Gurusamy, K. Samraj, C. Gluud, E. Wilson and B. R. Davidson, "Meta-Analysis of Randomized Controlled Trials on the Safety and Effectiveness of Early versus Delayed Laparoscopic Cholecystectomy for Acute Cholecystitis,” British Journal of Surgery, Vol. 97, No. 2, 2010, pp. 141-150. doi:10.1002/bjs.6870 